\title{
Single-cell transcriptomics reveal that PD-1 mediates immune tolerance by regulating proliferation of regulatory $\mathrm{T}$ cells
}

\author{
Cherry S. Leung ${ }^{1 \dagger}$, Kevin Y. Yang ${ }^{1 \dagger}$, Xisheng $\mathrm{Li}^{1}$, Vicken W. Chan ${ }^{1}$, Manching Ku${ }^{2}$, Herman Waldmann ${ }^{3}$,
} Shohei Hori ${ }^{4}$, Jason C. H. Tsang ${ }^{1,5}$, Yuk Ming Dennis Lo ${ }^{1,5}$ and Kathy O. Lui ${ }^{1,5^{*}}$ (D)

\begin{abstract}
Background: We have previously reported an antigen-specific protocol to induce transplant tolerance and linked suppression to human embryonic stem cell (hESC)-derived tissues in immunocompetent mice through coreceptor and costimulation blockade. However, the exact mechanisms of acquired immune tolerance in this model have remained unclear.

Methods: We utilize the NOD.Foxp $3^{\text {hCD2 }}$ reporter mouse line and an ablative anti-hCD2 antibody to ask if CD4 ${ }^{+} F O X P 3^{+}$ regulatory $T$ cells (Treg) are required for coreceptor and costimulation blockade-induced immune tolerance. We also perform genome-wide single-cell RNA-sequencing to interrogate Treg during immune rejection and tolerance and to indicate possible mechanisms involved in sustaining Treg function.

Results: We show that Treg are indispensable for tolerance induced by coreceptor and costimulation blockade as depletion of which with an anti-hCD2 antibody resulted in rejection of hESC-derived pancreatic islets in NOD.Foxp $3^{\text {hCD2 }}$ mice. Single-cell transcriptomic profiling of 12,964 intragraft $C D 4^{+} T$ cells derived from rejecting and tolerated grafts reveals that Treg are heterogeneous and functionally distinct in the two outcomes of transplant rejection and tolerance. Treg appear to mainly promote chemotactic and ubiquitin-dependent protein catabolism during transplant rejection while seeming to harness proliferative and immunosuppressive function during tolerance. We also demonstrate that this form of acquired transplant tolerance is associated with increased proliferation and PD-1 expression by Treg. Blocking PD1 signaling with a neutralizing anti-PD-1 antibody leads to reduced Treg proliferation and graft rejection.

Conclusions: Our results suggest that short-term coreceptor and costimulation blockade mediates immune tolerance to hESC-derived pancreatic islets by promoting Treg proliferation through engagement of PD-1. Our findings could give new insights into clinical development of hESC-derived pancreatic tissues, combined with immunotherapies that expand intragraft Treg, as a potentially sustainable alternative treatment for T1D.
\end{abstract}

Keywords: Single-cell transcriptomics, Transplant tolerance, CD4 $4^{+}$regulatory T cells, PD-1, Human pancreatic beta cells

\section{Background}

The global prevalence of diabetes was $8.5 \%$ in 2014 [1] and is predicted to rise due to the growing obesity epidemic. Although most type 1 (T1D) and some type 2 (T2D) diabetic patients receive insulin therapy, it does not

\footnotetext{
* Correspondence: kathyolui@cuhk.edu.hk

${ }^{+}$Cherry S. Leung and Kevin Y. Yang contributed equally to this work.

'Department of Chemical Pathology, Prince of Wales Hospital, The Chinese University of Hong Kong, Hong Kong, China

${ }^{5}$ Li Ka Shing Institute of Health Sciences, Prince of Wales Hospital, The

Chinese University of Hong Kong, Hong Kong, China

Full list of author information is available at the end of the article
}

provide a real-time glycemic control to patients compared to transplantation of glucose-sensing, insulin-secreting pancreatic islets so patients are still at risk of developing hypoglycemia and cardiovascular complications [2]. Transplantation of human cadaveric pancreatic islets has been implemented clinically $[3,4]$ with a majority of patients achieving insulin independence within the first year but declining rapidly afterwards [3, 4]. Any therapeutic efficacy of islet transplantation has also been largely limited by the scarcity and quality of donor islets, chronic immune rejection [3], and recurrence of autoimmunity [5].

(c) The Author(s). 2018 Open Access This article is distributed under the terms of the Creative Commons Attribution 4.0 International License (http://creativecommons.org/licenses/by/4.0/), which permits unrestricted use, distribution, and reproduction in any medium, provided you give appropriate credit to the original author(s) and the source, provide a link to the Creative Commons license, and indicate if changes were made. The Creative Commons Public Domain Dedication waiver (http://creativecommons.org/publicdomain/zero/1.0/) applies to the data made available in this article, unless otherwise stated. 
By virtue of their pluripotent and self-renewing properties, recent advances in human embryonic stem cell (hESC) technology have led to success in generating literally unlimited amount of human pancreatic endoderm cells or islets in vitro for transplantation, resulting in reversal of diabetes in mice [6-8]. Although transplantation of autologous induced pluripotent stem cell (iPSC) derivatives likely prevents immune rejection, T1D results from autoimmune attack so the T1D patient-specific iPSC-derived pancreatic beta cells might still harbor autoantigens to activate autoreactive memory $\mathrm{T}$ cells following transplantation [5]. On the other hand, direct presentation of autoantigens would be less likely with major histocompatibility complex (MHC) histoincompatible transplants. Moreover, cell therapy using derivatives of "off the shelf" hESCs is more economically and logistically feasible than hiPSCs when treating the population at large as well as patients with acute injuries [9]. Therefore, clinical trials using hESC derivatives $[10,11]$ and research in preventing their immune rejection still attract much attention $[9,12-14]$.

Transplantation of ESC-derived tissues also offers additional benefits [15-17] as they lack donor antigen-presenting cells (APCs) that elicit the direct pathway of allorecognition and are devoid of donor $\mathrm{T}$ cells that provoke graft-versus-host-disease (GVHD). All these features indicate that $\mathrm{hESC}$-derived pancreatic tissues could be less immunogenic than human cadaveric islets for transplantation. We have previously reported that ESC-derived tissues exhibit some degree of immune privilege and can be spontaneously accepted by allogeneic recipients in conditions including disparity for a class-I MHC molecule [18].

Recently, clinical trials using encapsulated hESC-derived pancreatic endoderm cells have been approved in T1D patients $[19,20]$. Cell encapsulation prevents direct contact between the transplanted cells and host immune system. Nevertheless, previous clinical studies have demonstrated that the therapeutic benefit of transplanting encapsulated human cadaveric islets into T1D patients is only temporary $[21,22]$. This is likely due to the host's innate immune response reacting to the implanted capsules, resulting in fibrosis, nutrient isolation, and donor tissue necrosis [23, 24]. To ensure long-term survival of the transplanted hESC-derived pancreatic tissues, particularly in autoimmune recipients with a primed immune system, the exploitation of endogenous tolerance processes will be invaluable.

One of the mechanisms by which antigen-specific immune tolerance established in mice operates through $\mathrm{CD}_{4}{ }^{+} \mathrm{FOXP}^{+}{ }^{+}$regulatory $\mathrm{T}$ cells (Treg). Treg are indispensable for maintaining peripheral self-tolerance [25] and are important in suppressing allogeneic responses against non-self antigens during GVHD [26] or allograft rejection [18, 27]. Following allogeneic transplantation,
Treg accumulating in tolerated grafts are immunosuppressive locally, can induce additional Treg (iTreg) from naïve $T$ cells via infectious tolerance [27, 28], and can protect "third-party" antigens that coexist with tolerated antigens from immune rejection via linked suppression [29]. In all these situations, the mechanisms sustaining Treg survival in vivo are not yet fully understood.

Furthermore, it is unclear what Treg are doing within rejecting grafts. Are they solely bystanders, or remnants of a failed suppressive endeavor, or even contributors to the rejecting processes? We have previously reported an antigen-specific protocol to induce transplant tolerance and linked suppression to hESC-derived endothelial cells and neurons following transplantation into immunocompetent mice using coreceptor and costimulation antibody blockade [13]. Here, we demonstrate that such antibody blockade also promoted transplant tolerance to hESC-derived pancreatic islets in non-obese diabetic (NOD) mice that involved the activity of Treg. Using single-cell RNA-sequencing (scRNA-seq), we performed genome-wide characterization of 12,964 intragraft $\mathrm{CD} 4^{+}$ $\mathrm{T}$ cells including conventional $\mathrm{T}$ cells and Treg of both rejecting and tolerated grafts. We show that conventional T cells found in the tolerated grafts expressed genes previously reported to support Treg function. Moreover, Treg were heterogeneous despite the beneficial transplant outcome. In contrast, there were at least two subsets of Treg in rejecting grafts that were distinct and less proliferative compared to those in tolerated grafts.

Our scRNA-seq data also show that antibody blockade augmented proliferation and PD-1 expression of Treg in tolerated grafts. Recently, immunotherapy targeting immune checkpoints including programmed cell death protein 1 (PD-1) has become a promising anti-cancer medicine. However, it has been reported that patients receiving anti-PD-1 antibodies developed T1D and other autoimmune diseases [30]. Although the role of PD-1 on conventional $\mathrm{T}$ cells has been well established [31], whether the PD-1 signaling can in some way affect Treg remains unclear. In this study, we observed that PD-1 blockade via a neutralizing anti-PD-1 antibody reduced proliferation of Treg and prevented tolerance induced by coreceptor and costimulation blockade. Taken together, our results suggest that coreceptor and costimulation blockade mediated transplant tolerance to hESC-derived pancreatic islets in NOD mice, at least in part, by promoting Treg proliferation via PD-1 signaling.

\section{Methods}

Human ESC cultures and pancreatic islet differentiation The H9 hESC line (WA09, WiCell) was maintained in mTseR1 medium (Stemgent). EB induction was performed by resuspending hESCs in differentiation medium containing DMEM/F12, 10\% knockout serum replacement 
(KOSR), 1X non-essential amino acids, 1X glutamine, 1X penicillin/streptomycin, and $1 \mathrm{X}$ b-mercaptoethanol (Gibco) in hanging drop cultures overnight. Individual EBs were then transferred to suspension cultures and incubated in differentiation medium containing 1\% KOSR for another 12 days before transplantation. For pancreatic islet differentiation, hESCs were differentiated by stepwise administration of growth factors as described previously [6]. Briefly, a combination of growth factors was supplemented as follows: day 1/S1: $100 \mathrm{ng} / \mathrm{ml}$ Activin A (Peprotech) $+3 \mu \mathrm{M}$ Chir99021 (Selleck Chem); day 2/S1: $100 \mathrm{ng} / \mathrm{ml}$ Activin A; days 4 and 6/S2: $50 \mathrm{ng} / \mathrm{ml} \mathrm{KGF} \mathrm{(Peprotech);} \mathrm{days} 7$ and 8/ S3: $50 \mathrm{ng} / \mathrm{ml} \mathrm{KGF}+0.25 \mu \mathrm{M}$ Sant1 (Sigma) $+2 \mu \mathrm{M}$ RA (Sigma) + 200 nM LDN193189 (Sigma, on day 7 only) + $500 \mathrm{nM}$ PdBU (EMD Millipore); days 9 and 11, 13/S3: 50 ng/ml KGF + $0.25 \mu \mathrm{M}$ Sant1 + 100 nM RA; days 14 and 16/S5: $0.25 \mu \mathrm{M}$ Sant1 + $100 \mathrm{nM} \mathrm{RA}+1 \mu \mathrm{M}$ XXI (Calbiochem) $+10 \mu \mathrm{M}$ Alk5i II (Selleck Chem) $+1 \mu \mathrm{M}$ T3 (EMD Millipore) $+20 \mathrm{ng} / \mathrm{ml}$ Betacellulin (Peprotech). Days 18 and 20/S5: $25 \mathrm{nM}$ RA $+1 \mu \mathrm{M}$ XXI + $10 \mu \mathrm{M}$ Alk5i II + $1 \mu \mathrm{M}$ T3 + 20 ng/ml Betacellulin. Days 21-35/S6 (medium changed on alternative days): $10 \mu \mathrm{M}$ Alk5i II $+1 \mu \mathrm{M}$ T3. In the final stage, cells were cultured in CMRL 1066 modified medium (CMRLM).

\section{Mice}

Foxp3 ${ }^{\text {hCD2 }}$ reporter mice $(\mathrm{C} 57 \mathrm{BL} / 6)$ [32] were backcrossed onto the NOD/ShiJc1 (Clea Japan. Inc) background for 12 generations. Experiments were performed with mice at 8-10 weeks old before onset of diabetes.

\section{Kidney capsule transplantation}

EBs or hESC-derived beta cell clusters were transplanted under the kidney capsule of NOD.Foxp $3^{\mathrm{hCD} 2}$ mice as described previously $[13,18]$.

\section{Administration of monoclonal antibodies}

Non-depleting mAb specific for CD4 (1 mg, clone YTS 177), CD8 (1 mg, clone YTS 105), and CD40L (1 mg, clone MR1, BioXcell) were injected intraperitoneally (i.p.) on days 0,2 , and 4 following transplantation. For Treg depletion, ablative anti-hCD2 mAb (0.25 mg, clone YTH655) was injected i.p. on days 0-7 following transplantation as previously described [27]. For PD1 blockade, neutralizing anti-PD1 mAb (0.5 mg, clone RMP114 , BioXcell) was injected i.p. on days $0,2,4,6$, and 8 following transplantation as previously described [33]. The hybridoma lines for making YTS177, YTS105, and YTH655 antibodies were prepared as previously described $[13,18,34]$.

\section{Immunostaining}

Kidney grafts were dissected and fixed in $4 \%$ paraformaldehyde at $4{ }^{\circ} \mathrm{C}$ overnight. The fixed grafts were washed three times with PBS and equilibrated in 30\% sucrose for 2 days before freezing and cryosectioning. Six-micrometer sections were blocked at $2 \%$ goat serum and then stained with the respective primary antibodies at $10 \mu \mathrm{g} / \mathrm{ml}$ at $4{ }^{\circ} \mathrm{C}$ overnight. Anti-human primary antibodies used are the following: PDX1 (R\&D systems), NKX6.1 (R\&D systems), GLUCAGON (Abcam), and C-PEPTIDE (DSHB), and the anti-mouse primary antibodies used are the following: Ki67 (eBiosciences) and FOXP3 (Cell Signaling Technology). Alexa-Fluor-488- or Alexa-Fluor-594-conjugated secondary antibodies (Invitrogen) were used at room temperature for $30 \mathrm{~min}$ in the dark. Slides were mounted with DAPI-containing fluorescence mounting medium (Dako), and fluorescence was detected with a confocal microscope (Leica). Some sections were also stained with hematoxylin and eosin (H\&E) for histological analyses.

\section{FACS sorting and analysis}

Splenocytes were dissociated by pressing the excised spleen in PBS with a syringe plunger through a 40- $\mu \mathrm{m}$ cell strainer to obtain single cell suspension. Single blood cells were dissociated from whole blood after removal of plasma in EDTA. Single graft cells were obtained by digesting the grafts with a digestion buffer containing collagenase II (11 U/ml, Worthington), dispase $(1000 \mathrm{U} / \mathrm{ml}$, Gibco), and DNase I (10 U) at $37{ }^{\circ} \mathrm{C}$ for $20-30 \mathrm{~min}$. Enzymatic action was stopped by adding $10 \%$ FBS, and the dissociated cells were washed twice with PBS. The dissociated single splenocytes, blood, or graft cells were removed from the contaminated erythrocytes by incubating with the red blood cell lysis buffer (eBiosciences) for $5 \mathrm{~min}$ and were then blocked with $2 \%$ heat-inactivated rabbit serum. Cells were subsequently stained with fluorochrome-conjugated antibodies against the following antigens: mCD3, mCD4, mPD1, or hCD2 (Biolegend) at a dilution of 1:100, unless specified by the manufacturer, at $4{ }^{\circ} \mathrm{C}$ for $30 \mathrm{~min}$. Murine Treg were detected with the Treg staining kit according to the manufacturer's instructions (eBioscience). Cells were then washed three times with $2 \%$ FBS-containing PBS and analyzed on flow cytometer (BD FACSAria $^{\mathrm{Tm}}$ Fusion). Propidium iodide (PI, BD) positive dead cells were excluded for live cell analysis/sorting, and FACS data were then analyzed with the FlowJo software (Tree star).

\section{Bulk RNA-sequencing and functional annotations}

Total RNA was isolated from FACS-sorted cells using the RNeasy mini kit (Qiagen) and analyzed on the Agilent Tape station for RNA Integrity Numbers (RIN) prior to library preparation. RNA-Seq libraries were prepared using TruSeq Stranded mRNA Library Prep Kit according to manufacturer's protocol (Illumina). mRNA was isolated using poly-T oligos conjugated to magnetic 
beads and then fragmented and reverse-transcribed to cDNA. dUTPs were incorporated during second-strand synthesis and thus not amplified. cDNA was then undergone end-repair, ligation with indexed adapters, and PCR amplification. Nucleic acid was cleaned up after each steps using AMPure XP beads (Beckman Coulter). Libraries were then quantified, pooled, and sequenced at single-end 50 base-pair on the Illumina HiSeq platform. Libraries were sequenced at an average depth of 20 million reads per library. After trimming low-quality bases, the sequenced reads were aligned to the mouse reference genome (mm10) using STAR (v2.4.2a) with default settings [35]. Reference genome and gene model file (mm10) were obtained from HOMER [36]. The expression abundances of all genes and differentially expressed genes were calculated by HOMER (v4.7) with default parameters. The identified differentially expressed genes were further annotated with Gene Ontology (GO) using DAVID Bioinformatics Resources (v6.8) [37].

\section{Single-cell encapsulation and library preparation}

Single cells were purified by FACS sorting before library preparation, and single-cell libraries were prepared with the Chromium Single Cell 3' Reagent Kits v2 (10x Genomics) as per manufacturer's instructions. Briefly, sorted cells in suspension were first prepared as gel beads in emulsion (GEMs) on Single Cell 3' Chips v2 (10x Chromium) using the Chromium Controller (10x Genomics). Barcoded RNA transcripts in each single cell were reverse transcribed within GEM droplets. cDNA was purified with DynaBeads MyOne Silane beads (Invitrogen) and then amplified for subsequent library construction. Sequencing libraries were prepared by fragmentation, end-repair, ligation with indexed adapters, and PCR amplification using the Chromium Single Cell 3' library kit v2 (10x Genomics). Nucleic acid was cleaned up after each steps using SPRIselect beads (Beckman Coulter). Libraries were then quantified by Qubit and real-time quantitative PCR on a LightCycler 96 System (Roche).

\section{Single-cell RNA-sequencing and functional annotations}

Pooled libraries were sequenced on the Illumina NextSeq 500 platform. All single-cell libraries were sequenced with a customized paired-end dual index format (98/26/0/8 basepair) according to manufacturer's instructions. Data were processed, aligned, and quantified using the Cell Ranger Single-Cell Software Suite (v 2.0) [38]. Briefly, data were demultiplexed based on the 8 base-pair sample index, 16 base-pair Chromium barcodes, and 10 base-pair unique molecular identifiers (UMI). Two distinct groups of contaminated cells were removed as they expressed genes of the myeloid lineage. To eliminate the impact of cell number bias, data from $\sim 1000$ cells of each sample were randomly selected for further analysis. Cells with either very low or too high mRNA content (i.e., out of two standard deviations) or high fractions of mitochondrial encoded transcripts (>10\%) were filtered out. Data were aligned on Mus musculus Cell Ranger transcriptome reference (mm10-1.2.0), and analyses, including PCA, tSNE, and graph-based clustering, were performed according to Cell Ranger's pipelines with default settings. To perform differential expression analysis on each comparison, Cell Ranger's pipelines were applied with sSeq algorithm [39], which employs a negative binomial exact test to generate $p$ values and further adjusted using Benjamini-Hochberg. To perform GO functional enrichment analysis, genes that satisfy a less stringent criterion (with at least fourfold changes) were considered to be potential targets, which were further annotated with GO using DAVID Bioinformatics Resources (v6.8) [37]. Cell cycle phase classifications were performed by scran [40] with default settings.

\section{Statistical analysis}

The data were expressed as arithmetic mean \pm s.d. of biological replicates ( $n=6$, unless otherwise specified) performed under the same conditions. Statistical analysis was performed using the unpaired Student's $t$ test with data from two groups, while data from more than two groups was performed using an ANOVA followed by Tukey's method for multiple comparisons. Significance was accepted when $P<0.05$.

\section{Results}

Coreceptor and costimulation blockade facilitates survival and maturation of hESC-islets in NOD mice

We have previously reported that coreceptor and costimulation blockade induces transplant tolerance and linked suppression to hESC-derived progenitor cells and their differentiated progenies in immunocompetent mice [13]. To ask if the same regimen protects grafts from rejection in mice with an autoimmune background such as NOD, we transplanted surrogate hESC-derived embryoid bodies (hESC-EB) under the kidney capsule of 10-week-old NOD mice under cover of treatment with anti-CD4, anti-CD8, and anti-CD40L monoclonal antibodies $(3 \mathrm{mAb})$, previously shown to allow transplants to survive for at least 3 months as previously described [13]. We found that hESC-EB survived and differentiated into three embryonic germ layers at 1 month after transplantation (Additional file 1: Figure S1), indicating that coreceptor and costimulation blockade induced graft acceptance in NOD mice. In fact, coreceptor blockade alone can reverse hyperglycemia in NOD mice as previously described [41]. Moreover, we differentiated pancreatic islets from hESCs (hESC-islets) as a surrogate tissue for transplantation (Fig. 1a) using a protocol previously demonstrated to reverse streptozotocin-induced hyperglycemia 

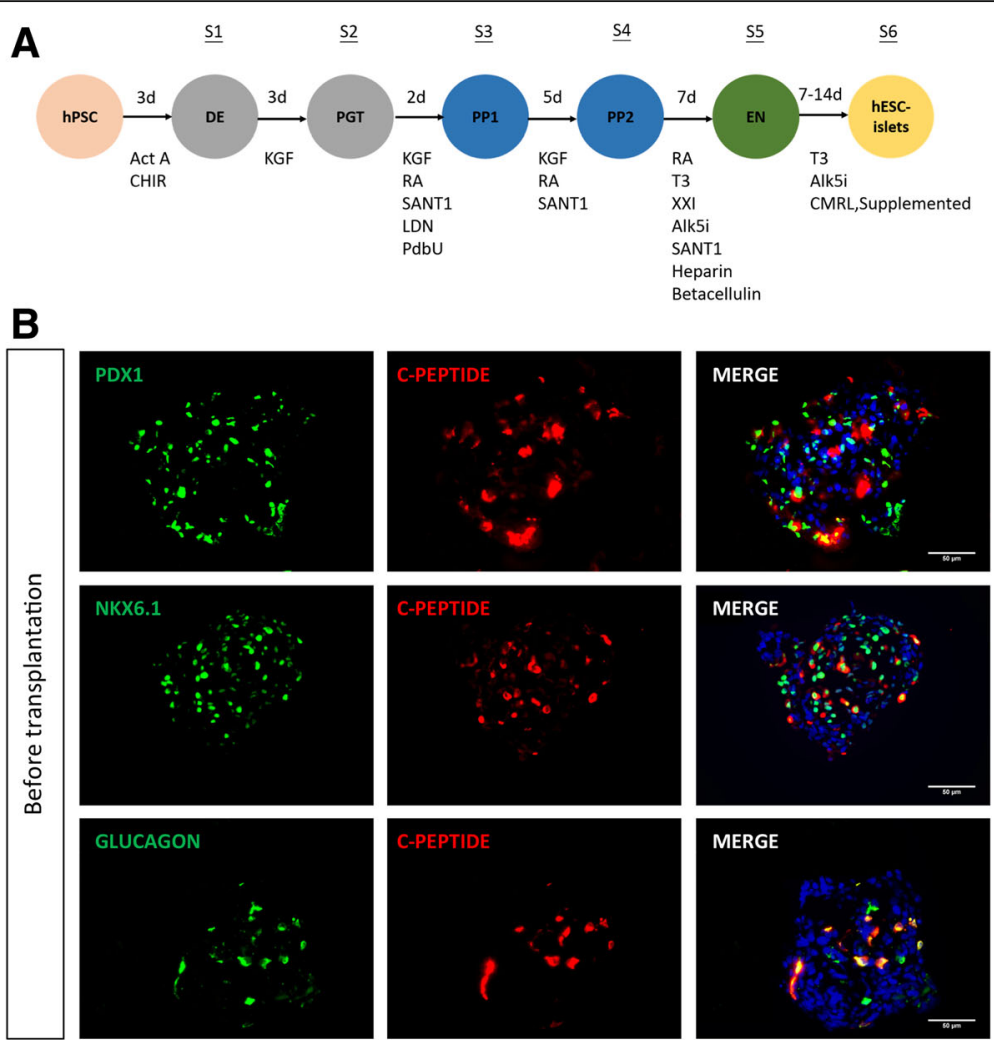

C
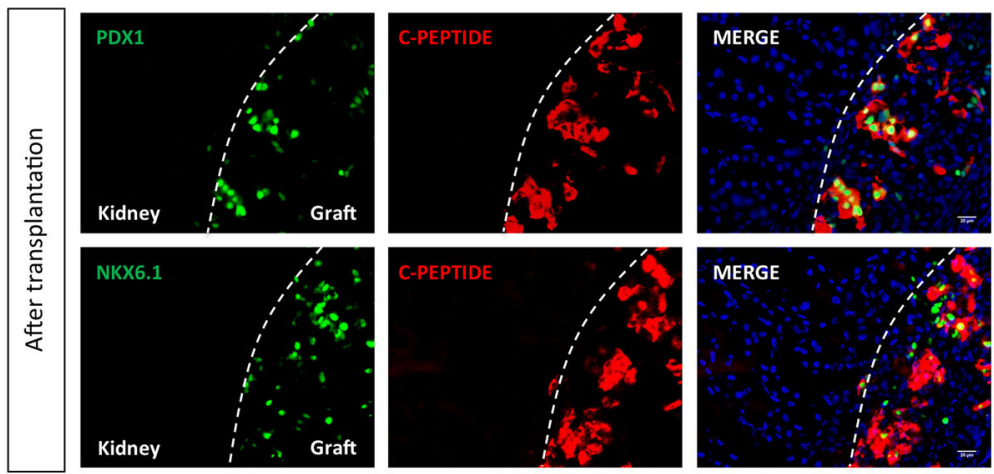

Fig. 1 Coreceptor and costimulation blockade facilitates survival and maturation of hESC-derived pancreatic islets in NOD.Foxp $3^{\text {hCD2 }}$ mice. a A schematic diagram showing the simplified stepwise differentiation protocol to generate human pancreatic islets from hESCs. b, c Immunostaining for the lineage-specific markers of human pancreatic islets $\mathbf{b}$ before and $\mathbf{c}$ after 1-month transplantation of hESC-islets in NOD.FOxp $3^{\text {hCD2 }}$ mice $(n=6)$ following treatment with coreceptor and costimulation blockade. Scale bars in b: $50 \mu \mathrm{m}$ and in c: $20 \mu \mathrm{m}$

[6]. Whether the surrogate tissue reversed hyperglycemia was not the focus of this study as both the tolerance induction regimen and surrogate tissues facilitate remission of diabetes. Rather, we studied the mechanisms by which coreceptor and costimulation blockade induced transplant tolerance to hESC-derived tissues. This is why we transplanted 10-week-old NOD mice, well before the onset of diabetes, to minimize the risk that autoimmune reactions might alter analysis of mechanisms operated during induction of transplant tolerance.
Immunostaining for human PDX1, NKX6.1, or GLUCAGON with C-PEPTIDE, respectively, in stage 6 cells confirmed differentiation of hESCs into hESC-islets (Fig. 1b). We then transplanted hESC-islets under cover of treatment with $3 \mathrm{mAb}$ and found that hESC-islets survived in NOD mice without teratoma formation (Fig. 1c). Moreover, immunostaining for human PDX1 or NKX6.1 with C-PEPTIDE in tolerated grafts revealed that $\mathrm{hESC}$-islets matured in vivo as there were more $\mathrm{PDX} 1^{+} \mathrm{C}-\mathrm{PEPTIDE}^{+}$or NKX6. $1^{+}$C-PEPTIDE ${ }^{+}$cells in tolerated grafts (Fig. 1c) than 
those before transplantation (Fig. 1b). Our results demonstrated that $\mathrm{hESC}$-islets served as a surrogate tissue for downstream analysis, and coreceptor and costimulation blockade induced transplant tolerance to hESC-derived tissues not only in wildtype but also in recipients of T1D background not yet exhibiting autoimmune disease.

\section{Coreceptor and costimulation blockade promotes transplant tolerance to hESC-derived tissues through $\mathrm{CD}^{+}{ }^{+}$Treg}

Although Treg deficiency or dysfunction is sufficient to break self-tolerance [25], it remains unclear whether they are indispensable for maintaining transplant tolerance to hESC-derived tissues. Previously, we were unable to detect $\mathrm{CD}^{+}{ }^{+} \mathrm{FOXP}_{3}{ }^{+}$Treg in rejecting grafts and very few were detected in tolerated grafts [13] due to cell loss through intra-nuclear immunostaining for FOXP3 and to a lack of reliable cell surface marker(s) for phenotyping of murine $\mathrm{CD}^{+}{ }^{+}$Treg. To examine contribution of Treg in coreceptor and costimulation blockade-mediated transplant tolerance to hESC-derived tissues, we backcrossed the Foxp $3^{\mathrm{hCD} 2}$ reporter "knockin" allele [32] onto the NOD background, which allowed us to purify Treg via their surface expression of hCD2. We first confirmed co-localization of FOXP3 and hCD2 in NOD.Foxp $3^{\text {hCD2}}$ mice by flow cytometry (Fig. 2ba). We also detected $\mathrm{CD} 4^{+} \mathrm{hCD} 2^{+}$Treg in both rejecting and tolerated hESC-derived grafts (Fig. 2), while there was no significant difference in percentage of $\mathrm{CD} 4^{+} \mathrm{hCD} 2^{-}$conventional $\mathrm{T}$ cells (Th) of rejecting and tolerated grafts (Fig. 2c); a significantly higher percentage of $\mathrm{CD} 4^{+} \mathrm{hCD} 2^{+}$Treg was found in tolerated than rejecting grafts (Fig. $2 \mathrm{~d}$ ).

To determine if Treg were necessary for antibody-mediated tolerance, we depleted them with an ablative anti-hCD2 mAb ( $\alpha$ hCD2, Fig. $2 \mathrm{e}$ ). On day 4 post- $\alpha \mathrm{hCD} 2$ treatment, we already observed a threefold and fivefold reduction in splenic and circulatory $\mathrm{CD}^{+}{ }^{+} \mathrm{FOXP}^{+}$Treg within the $\mathrm{CD}^{+}$population, respectively (Fig. 2f). In fact, the depletion efficiency of Treg by $\alpha \mathrm{hCD} 2$ in NOD.Foxp3 ${ }^{\text {hCD2 }}$ (Fig. 2g) was comparable to that in B6.Foxp $3^{\text {hCD2}}$ as previously described [27]. We then transplanted hESC-islets in NOD.Foxp $3^{\mathrm{hCD} 2}$ and examined graft survival at 1 month following transplantation with 3 $\mathrm{mAb}$ or $3 \mathrm{mAb}+\alpha \mathrm{hCD} 2 \mathrm{mAb}$. Compared to grafts derived from $3 \mathrm{mAb}$-treated group that were $100 \%$ accepted, those from $3 \mathrm{mAb}+\alpha \mathrm{hCD} 2 \mathrm{mAb}$-treated group were $100 \%$ rejected ( $n=6$ per group, Fig. 2 h). Our results indicated that Treg were indispensable for coreceptor and costimulation blockade-induced transplant tolerance.

Genome-wide transcriptomic profiling of splenic CD4 ${ }^{+}$Treg during transplant rejection and tolerance

We next asked if Treg were beginning to influence transplant outcome in secondary lymphoid tissues by purifying splenic $\mathrm{CD}^{+}{ }^{+} \mathrm{hCD} 2^{+}$Treg from $3 \mathrm{mAb}+$ ahCD2 mAb-treated rejecting and $3 \mathrm{mAb}$-treated tolerized NOD.Foxp $3^{\mathrm{hCD} 2}$ following transplantation for bulk RNA-seq. We found 43 differentially expressed genes (Additional file 1: Figure S2), and functional annotations by GO showed that the most significantly downregulated genes in splenic Treg of tolerized compared to rejecting mice were associated with neutrophil chemotaxis (Csf $3 r$, Ccl1, Itga1, Il1b, Ccl5), angiogenesis (Mmp9, Il1b, Lrg1, $C c l 5)$, and regulation of $\mathrm{T}$ cell proliferation $(\mathrm{Il} 21, \mathrm{Il} 1 \mathrm{~b}$, Ccl5). Even though a total of 24,020 genes were identified in splenic Treg, this paucity of differentially expressed genes might indicate that Treg were largely similar in secondary lymphoid tissues during transplant rejection and tolerance.

\section{Genome-wide transcriptomic profiling of intragraft $\mathrm{CD}^{+}$ Th and Treg during transplant rejection and tolerance at single-cell resolution}

Previous reports have suggested that Treg-mediated tolerance to allogeneic skin grafts mainly operates at the graft site [27, 42]; however, the identities and interrelationships of different $\mathrm{CD} 4^{+} \mathrm{T}$ cell subsets at the graft site during transplant rejection and tolerance have not been studied. The definition of different $\mathrm{CD}^{+} \mathrm{T}$ cell subsets is likely biased due to insufficient surface markers for their purification and manipulation. To overcome this, we sought to understand the heterogeneity of $\mathrm{CD}^{+}{ }^{+} \mathrm{T}$ cells through large-scale droplet-based single-cell transcriptomic profiling $[38,43]$. In this system, individual cells were encapsulated in microfluidic droplets with unique nucleotide barcodes and molecule identifiers (UMI) for tagging RNAs inside the droplets. We purified about $\sim 12,964$ intragraft $\mathrm{CD}^{+}{ }^{+} \mathrm{T}$ cells by FACS including $858 \mathrm{CD}^{+} \mathrm{hCD}^{-}$helper $\mathrm{T}$ cells (Th) and 954 $\mathrm{CD} 4^{+} \mathrm{hCD} 2^{+}$Treg from ten recipients with rejecting grafts (untreated controls) and 3654 Th and 7498 Treg from ten recipients with tolerated grafts $(3 \mathrm{mAb}$ treated). It is worthy of note that untreated mice were used as rejecting controls as Treg depletion via anti-hCD2 antibodies could change the $\mathrm{T}$ cell populations within the grafts that could interfere our heterogeneity analysis. Moreover, to eliminate the impact of cell number bias, data from $\sim 1000$ cells of each sample were randomly selected for further analysis (Additional file 1: Figure S3).

We defined four cell clusters according to their initial CD4 and hCD2 expression and performed unsupervised analysis that did not rely on other known $\mathrm{CD}^{+}{ }^{+} \mathrm{T}$ cell subset markers. From the $t$-distributed stochastic neighbor embedding ( $t$-SNE) plots, we observed that $\mathrm{CD} 4{ }^{+} \mathrm{hCD} 2^{-}$Th $\left(\mathrm{R}-\mathrm{T}_{\mathrm{H}}\right)$ and $\mathrm{CD} 4^{+} \mathrm{hCD} 2^{+}$Treg $\left(\mathrm{R}-\mathrm{T}_{\mathrm{R}}\right)$ of rejecting grafts mapped closely together; $\mathrm{CD} 4^{+} \mathrm{hCD} 2^{-}$ Th of tolerated grafts $\left(T-T_{H}\right)$ mapped closer to $R-T_{H}$ and $\mathrm{R}-\mathrm{T}_{\mathrm{R}}$ than $\mathrm{CD} 4^{+} \mathrm{hCD} 2^{+}$Treg of tolerated grafts 

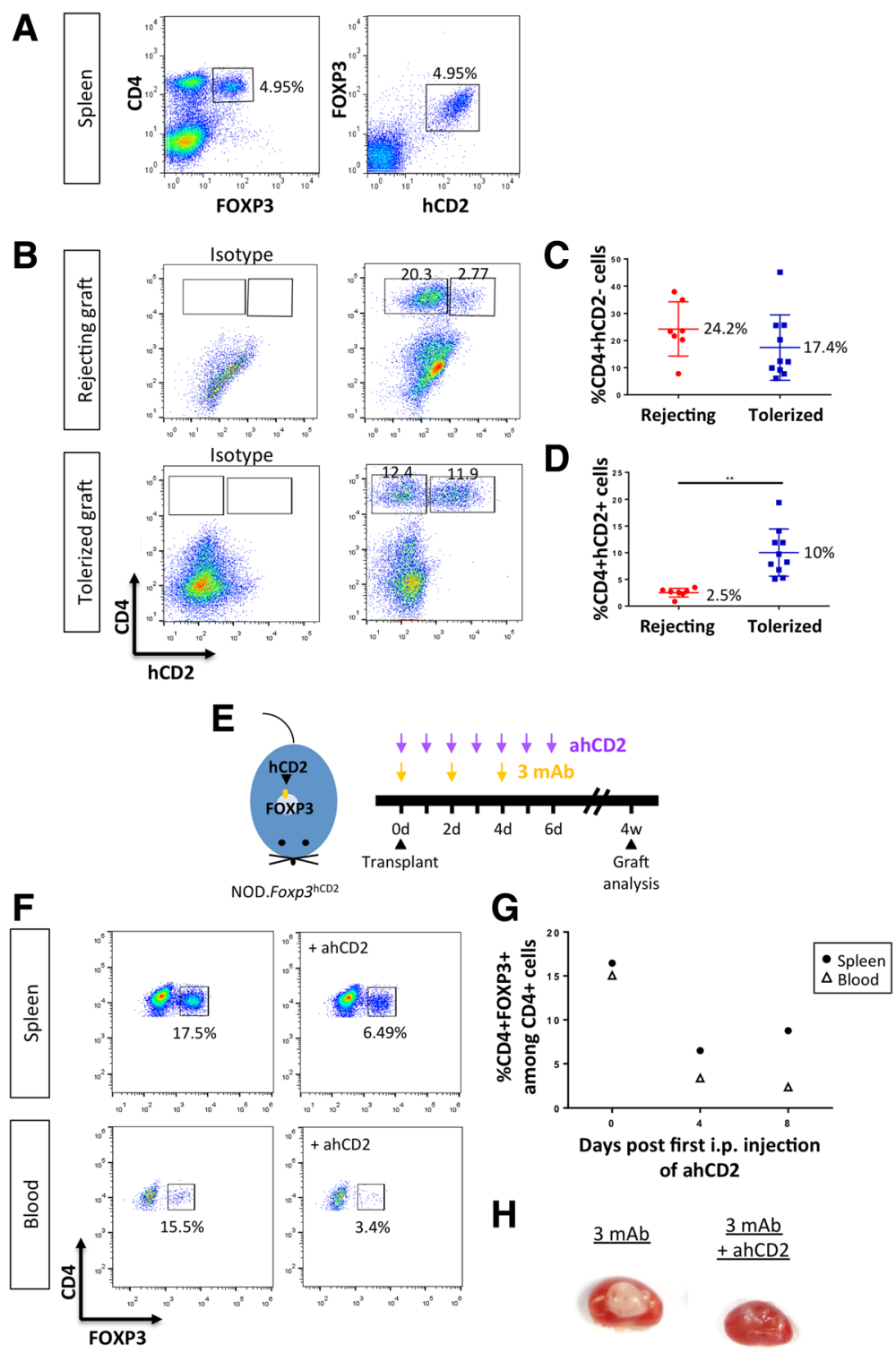

Fig. 2 Coreceptor and costimulation blockade promotes transplant tolerance to hESC-derived tissues through CD4 ${ }^{+}$Treg. a Flow cytometric analysis showing surface expression of hCD2 by all CD4 ${ }^{+} \mathrm{FOXP3}^{+}$Treg in NOD.Foxp $3^{\text {hCD2 }}$ mice. b Flow cytometric analysis and $\mathbf{c}$, $\mathbf{d}$ quantifications showing c comparable infiltration of $\mathrm{CD}^{+} h C D 2^{-}$conventional T cells but $\mathbf{d}$ significantly increased infiltration of $\mathrm{CD} 4^{+} h \mathrm{hD} 2^{+}$Treg in tolerated $(n=10)$ than rejecting $(n=10)$ grafts at 1 month post-transplantation. ${ }^{*} P<0.01$. e A schematic diagram showing the protocol for antibody treatments. $\mathbf{f}$ Flow cytometric analysis and $\mathbf{g}$ time-dependent quantifications showing reduced percentage of CD4 ${ }^{+} \mathrm{FOXP3} 3^{+}$Treg among total $\mathrm{CD}^{+} \mathrm{T}$ cells in the spleen and blood of NOD.Foxp $3^{\mathrm{hCD} 2}$ mice after treatment with the ablative ahCD2 antibody. $\mathbf{h}$ Representative images showing that ahCD2 antibody abolished coreceptor and costimulation blockade-mediated tolerance to hESC-islets at 1 month following transplantation, $n=6$ per group

$\left(\mathrm{T}-\mathrm{T}_{\mathrm{R}}\right.$ ); and $\mathrm{T}-\mathrm{T}_{\mathrm{R}}$ formed a distinct population (Fig. 3a). Based on their cytokine expression profiles, we further characterized $\mathrm{CD}_{4}^{+}$Th subsets during transplant rejection and tolerance. $\mathrm{R}-\mathrm{T}_{\mathrm{H}}$ included Ifng-expressing Th1 cells, Il4, Il5, and Il13-expressing Th2 cells as well as Il21-expressing Th17 cells during rejection, and $T-\mathrm{T}_{\mathrm{H}}$ mainly included Ifng-expressing Th1 cells as well as Il21-expressing Th17 cells during tolerance (Additional file 1: Figure S4A).
Next, we performed pairwise analysis to identify the differentially expressed genes. Although $R-T_{H}$ and $T-T_{H}$ did not form distinct clusters on $t$-SNE (Additional file 1: Figure S5A), 392 differentially expressed genes were identified in $\mathrm{T}-\mathrm{T}_{\mathrm{H}}$ compared to $\mathrm{R}-\mathrm{T}_{\mathrm{H}}$ and $\mathrm{GO}$ functional annotations showed that the most significantly upregulated pathway was associated with negative regulation of the immune system such as expression of $C d 81$ [44] and Ccr7 [45] that support Treg function or Tmem176a and 

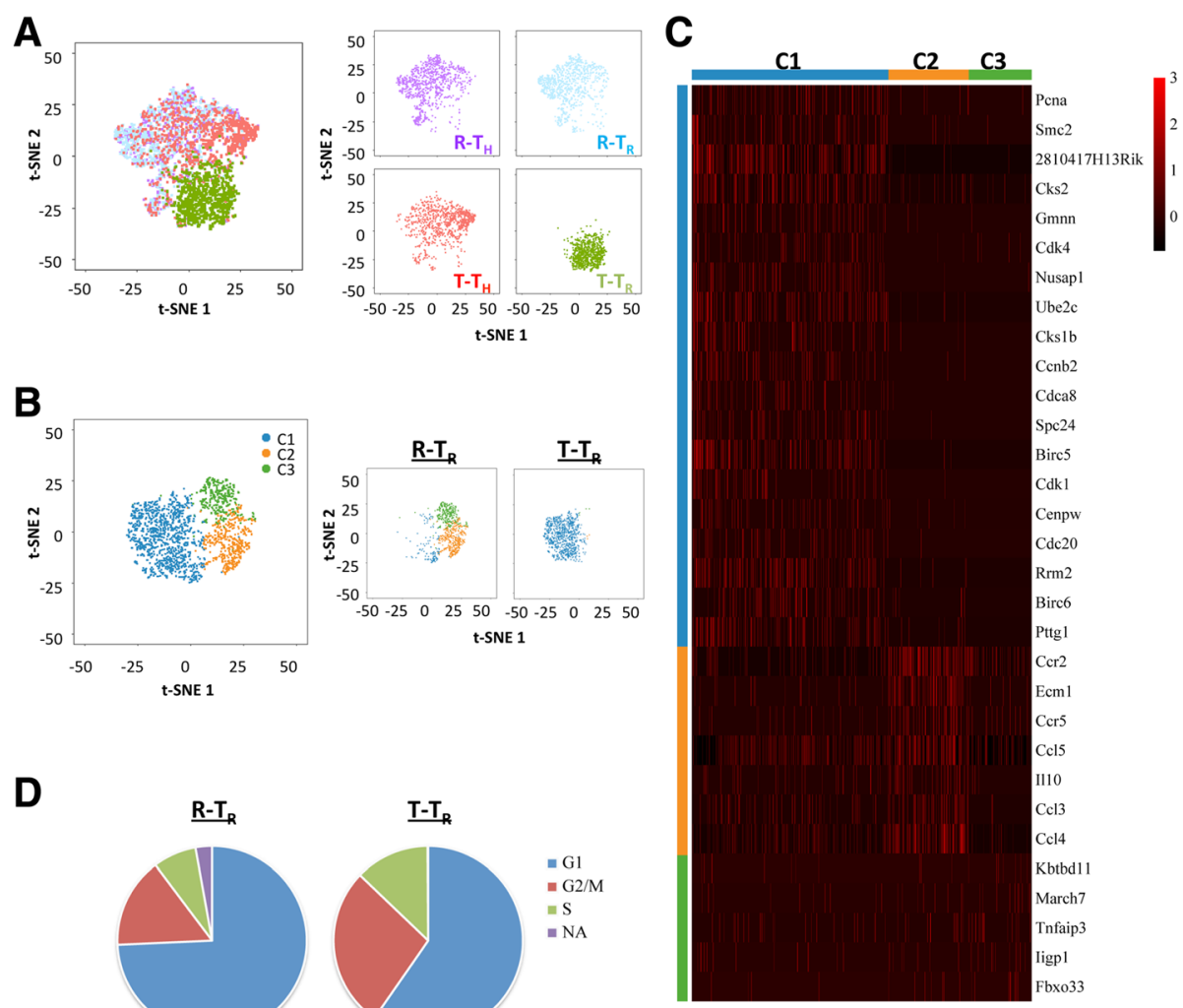

D
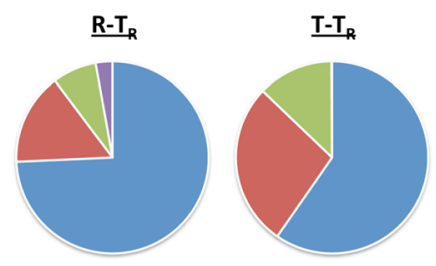

$\because \mathrm{G} 1$

$=\mathrm{G} 2 / \mathrm{M}$

$=$ NA

(n)

\section{E}
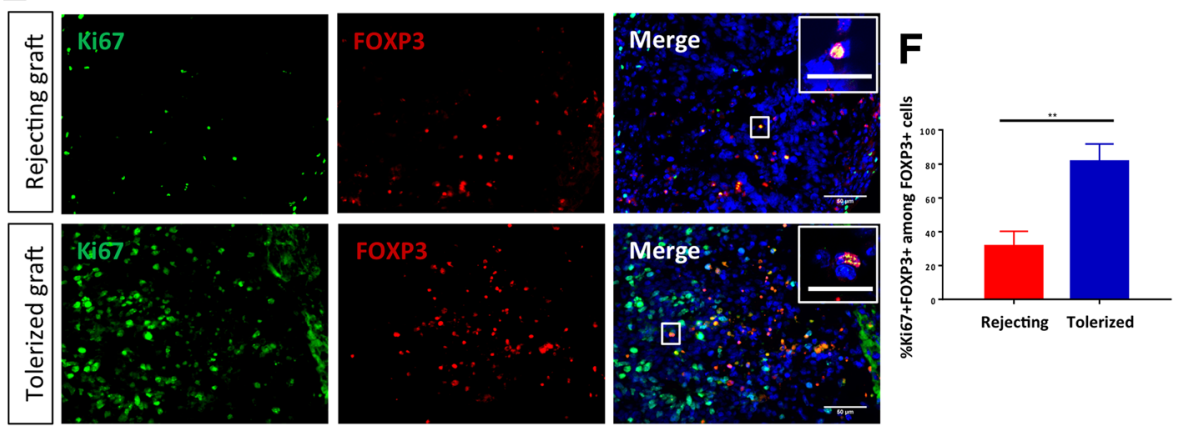

Fig. 3 Coreceptor and costimulation blockade-induced transplant tolerance is predominantly mediated by intragraft proliferation of CD4 ${ }^{+}$Treg. a Biaxial scatter plots by $t$-SNE analysis showing single-cell transcriptomic clustering of $\sim 1000 \mathrm{CD}^{+} h C D 2^{-}\left(\mathrm{T}_{H}\right)$ or $\sim 1000 \mathrm{CD}^{+} \mathrm{hCD} 2^{+}\left(\mathrm{T}_{R}\right)$ cells purified from rejecting and tolerated grafts, respectively. Cells were colored individually according to their initial expression of CD4 and hCD2 during FACS sorting. $\mathbf{b} t$-SNE analysis showing single-cell transcriptomic clustering of $\sim 1000 \mathrm{CD} 4^{+} h C D 2^{+}$Treg cells during transplant rejection and tolerance, respectively. Cells were further subgrouped into specific clusters (C1-4) and colored individually according to expression patterns of specific marker genes and spatial proximity in the biaxial plot. c From selected pathways determined by GO functional annotations in terms of biological processes of each cluster (Additional file 1: Tables S4-S6), upregulated genes with an average expression level >0.05 were displayed by the heatmap. $\mathbf{d}$ Scran analysis showing cell cycle phase classifications. e Immunostaining and $\mathbf{f}$ quantifications of Ki6 $7^{+} \mathrm{FOXP} 3^{+}$cells among total $\mathrm{FOXP3}^{+}$cells in rejecting and tolerated grafts. Inserts denote magnified Ki67 $7^{+} \mathrm{FOXP}^{+}$cells. Scale bars in e: $50 \mu \mathrm{m}$ and inserts: $10 \mu \mathrm{m}$. $n=6$ per

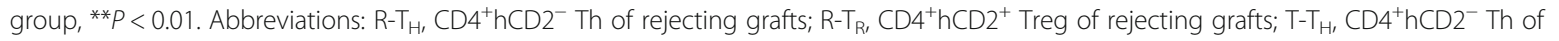
tolerated grafts; and $\mathrm{T}-\mathrm{T}_{\mathrm{R}}, \mathrm{CD} 4^{+} \mathrm{hCD} 2^{+}$Treg of tolerated grafts

Tmem176b that negatively regulate dendritic cell differentiation. Moreover, the most significantly downregulated pathways were associated with responses to interferon- $\alpha / \beta / \gamma$ (Additional file 1: Figure S5B, gene listed in Additional file 1: Table S1). Therefore, $\mathrm{CD} 4^{+}$Th cells might, perhaps, elicit more immunomodulatory than inflammatory responses during transplant tolerance than rejection.

During transplant rejection, we found that $R-T_{R}$ and $\mathrm{R}-\mathrm{T}_{\mathrm{H}}$ mapped closely together on $t$-SNE (Additional file 1 : 
Figure S5C). A total of 367 differentially expressed genes were identified in $R-T_{R}$ compared to $R-T_{H}$, and $G O$ functional annotations showed that the most significantly upregulated pathways were associated with negative regulation of conventional $\mathrm{T}$ cell function (e.g., Cd81, Phlpp1, Foxp3, Sdc4, and Il2ra) and the most significantly downregulated pathways were associated with adaptive immune responses (e.g., Cd40Ig, Il2, Il4, Ifng), DNA repair, and autophagy (Additional file 1: Figure S5D, gene listed in Additional file 1: Table S2). Compared to $\mathrm{CD}^{+}{ }^{+}$Th cells, Treg during transplant rejection could still harbor anti-inflammatory functions.

During transplant tolerance, we found that $T-T_{R}$ and $\mathrm{T}-\mathrm{T}_{\mathrm{H}}$ formed distinct clusters on $t$-SNE (Additional file 1: Figure S5E). A total of 565 differentially expressed genes were identified in $T-T_{R}$ compared to $T-T_{H}$, and GO functional annotations showed that the most significantly upregulated pathways were associated with cell proliferation and antigen presentation via MHC-II (e.g., $H 2-A a, C d 74$, $H 2-A b 1$, Ifi30, H2-Eb1) and the most significantly downregulated pathways were associated with regulation of $\mathrm{B}$ cell/T cell proliferation (e.g., Cd40Ig, Nckap1l, Tnfsf13b, Tnfrsf13c, Bcl2, Bmi1, Ccl5, Cd274) and NK cell chemotaxis (e.g., Ccl3, Ccl5, Xcl1, Additional file 1: Figure S5F, gene listed in Additional file 1: Table S3). Compared to $\mathrm{CD}^{+}$Th cells, Treg during transplant tolerance could replicate with immunosuppressive functions.

\section{Intragraft $\mathrm{CD}^{+}$Treg are phenotypically and functionally distinct during transplant rejection and tolerance}

To further examine whether Treg are bystanders during transplant rejection, we identified their specific phenotypic and functional differences by comparing their transcriptomic signatures during transplant tolerance. In addition to FOXP3/hCD2, R- $T_{R}$ and $T-T_{R}$ also expressed other Treg markers including Il2ra, Ikzf2, Nrp1, and Il10 (Additional file 1: Figure S4B). Nevertheless, they formed distinct clusters on $t$-SNE: all T-T $T_{R}$ but few $\mathrm{R}-\mathrm{T}_{\mathrm{R}}$ formed cluster $\mathrm{C} 1$, and a majority of $\mathrm{R}-\mathrm{T}_{\mathrm{R}}$ formed clusters $\mathrm{C} 2$ and $\mathrm{C} 3$ (Fig. 3b, Table 1). Comparing differentially expressed genes of these clusters by $\mathrm{GO}$ functional annotations, $\mathrm{C} 1$ was distinguished from the other clusters by upregulated cell cycle/cell division genes and downregulated inflammatory/chemotactic genes

Table 1 Distribution of cell number and percentage of CD4 ${ }^{+}$ Treg during rejection and tolerance in each cell cluster as determined by $t$-SNE

\begin{tabular}{|c|c|c|c|c|c|}
\hline Cluster & Total cell number (\#) & $\# R-T_{R}$ & $\# \mathrm{~T}-\mathrm{T}_{\mathrm{R}}$ & $\% R-T_{R}$ & $\% \mathrm{~T}-\mathrm{T}_{\mathrm{R}}$ \\
\hline 1 & 1086 & 134 & 952 & 14.6 & 99.27 \\
\hline 2 & 444 & 441 & 3 & 48.04 & 0.31 \\
\hline 3 & 347 & 343 & 4 & 37.36 & 0.42 \\
\hline
\end{tabular}

as demonstrated by heat map (Fig. 3c) and pathway analyses (Additional file 1: Figure S6A, gene listed in Additional file 1: Table S4). Similarly, C2 was marked by upregulated chemotactic/chemokine genes and downregulated cell cycle/cell division genes (Additional file 1: Figure S6B, gene listed in Additional file 1: Table S5); C3 was characterized by upregulated genes regulating protein ubiquitination and responses to interferons and downregulated DNA/cell proliferation genes (Additional file 1: Figure S6C, gene listed in Additional file 1: Table S6). Altogether, with unbiased transcriptomic classification of FOXP3-expressing $\mathrm{R}-\mathrm{T}_{\mathrm{R}}$ and $\mathrm{T}-\mathrm{T}_{\mathrm{R}}$, we discovered that Treg could be more heterogeneous during transplant rejection than tolerance and they skewed away from replicating, immunosuppressive $\mathrm{C} 1$ to less replicating, chemotactic $\mathrm{C} 2$ or ubiquitination-prone $\mathrm{C} 3$.

\section{Coreceptor and costimulation blockade-induced transplant tolerance is associated with intragraft proliferation of $\mathrm{CD}^{+}$ Treg}

We also performed cell cycle phase classification analyses with the scRNA-seq data of $R-T_{R}$ and $T-T_{R}$ by Scran (Fig. 3d, Table 2). Our results showed that a larger proportion of $\mathrm{T}-\mathrm{T}_{\mathrm{R}}(\sim 40 \%)$ than $\mathrm{R}-\mathrm{T}_{\mathrm{R}}(\sim 22 \%)$ was found in the S-G2/M phases, implying DNA/cell proliferation. Moreover, we also validated our transcriptomic results by immunostaining for the proliferation marker Ki67 (Fig. 3e). Indeed, our results revealed that significantly more $\mathrm{Ki} 67^{+} \mathrm{FOXP3}^{+}$Treg could be found in tolerated than rejecting grafts (Fig. 3f). Therefore, it is likely that Treg proliferation was a significant mechanism by which coreceptor and costimulation blockade induced transplant tolerance to hESC-derived tissues.

\section{Proliferation of $\mathrm{CD}^{+}$Treg in tolerated grafts requires functional PD-1 signaling}

We then examined the mechanisms by which coreceptor and costimulation blockade induced tolerance through promoting intragraft Treg proliferation. From our transcriptomic profiling data, we observed that expression of $P d c d 1 / P D-1$ significantly increased while expression of

Table 2 Distribution of cell number and percentage of $\mathrm{CD}^{+}$ Treg during rejection and tolerance in each of the cell cycle phases as determined by Scran

\begin{tabular}{|c|c|c|c|c|}
\hline & $\# \mathrm{R}-\mathrm{T}_{\mathrm{R}}$ & $\# \mathrm{~T}-\mathrm{T}_{\mathrm{R}}$ & $\% R-T_{R}$ & $\% \mathrm{~T}-\mathrm{T}_{\mathrm{R}}$ \\
\hline Total cell number (\#) & 918 & 959 & & \\
\hline G1 & 682 & 572 & 74.29 & 59.65 \\
\hline G2M & 142 & 264 & 15.47 & 27.53 \\
\hline$S$ & 68 & 122 & 7.41 & 12.72 \\
\hline NA & 26 & 1 & 2.83 & 0.1 \\
\hline
\end{tabular}


other stimulatory (Tnfrsf18/GITR, Icos) and inhibitory (Ctla4, Lag3, Havcr2/TIM-3) checkpoint molecules remained relatively stable or significantly reduced in $\mathrm{CD}^{+}{ }^{+} \mathrm{T}$ cells during transplant tolerance compared to rejection (Fig. 4). We, therefore, focused on PD-1 for functional validation. We confirmed our scRNA-seq results by flow cytometry that a significantly greater percentage of $\mathrm{PD}-1^{+} \mathrm{CD} 4^{+} \mathrm{hCD} 2^{+}$population was found in tolerated than rejecting grafts, suggesting that coreceptor and costimulation blockade increased PD-1 expression by Treg during tolerance (Fig. 5a, b). Moreover, it appears that there was significantly higher PD-1 expression by $\mathrm{CD} 4^{+} \mathrm{hCD} 2^{-}$than $\mathrm{CD} 4^{+} \mathrm{hCD} 2^{+}$cells during rejection and vice versa during tolerance (Fig. 5b), implying that PD-1 was more predominantly expressed by the subset responsible for determining transplant outcome, i.e., more PD-1 expressed by Th during rejection and by Treg during tolerance.
With advances in immunotherapy using $\alpha \mathrm{PD}-1 \mathrm{mAb}$ in cancer patients, the inhibitory role of PD-1 signaling on conventional $\mathrm{T}$ cell activation has been well characterized [31]. However, whether PD-1 signaling regulates Treg proliferation and function, especially in the transplantation setting, remains elusive. To address this, we transplanted hESC-derived tissues in NOD.Foxp $3^{\mathrm{hCD} 2}$ and examined graft survival in the $3 \mathrm{mAb}-$ or $3 \mathrm{mAb}+\alpha \mathrm{PD}-1 \mathrm{mAb}$ treated group at 1 month following transplantation (Fig. 5c). Compared to grafts derived from $3 \mathrm{mAb}$-treated group that were $100 \%$ accepted, blocking PD-1 signaling by $\alpha \mathrm{PD}-1 \mathrm{mAb}$ resulted in graft rejection $(n=5$ per group, Fig. 5d). To investigate if PD-1 signaling regulated coreceptor and costimulation blockade-induced Treg proliferation, we performed immunostaining for Ki67 and FOXP3 in grafts derived from recipients treated with $3 \mathrm{mAb}$ or 3 $\mathrm{mAb}+\alpha \mathrm{PD}-1 \mathrm{mAb}$ (Fig. 5e). Our results revealed that

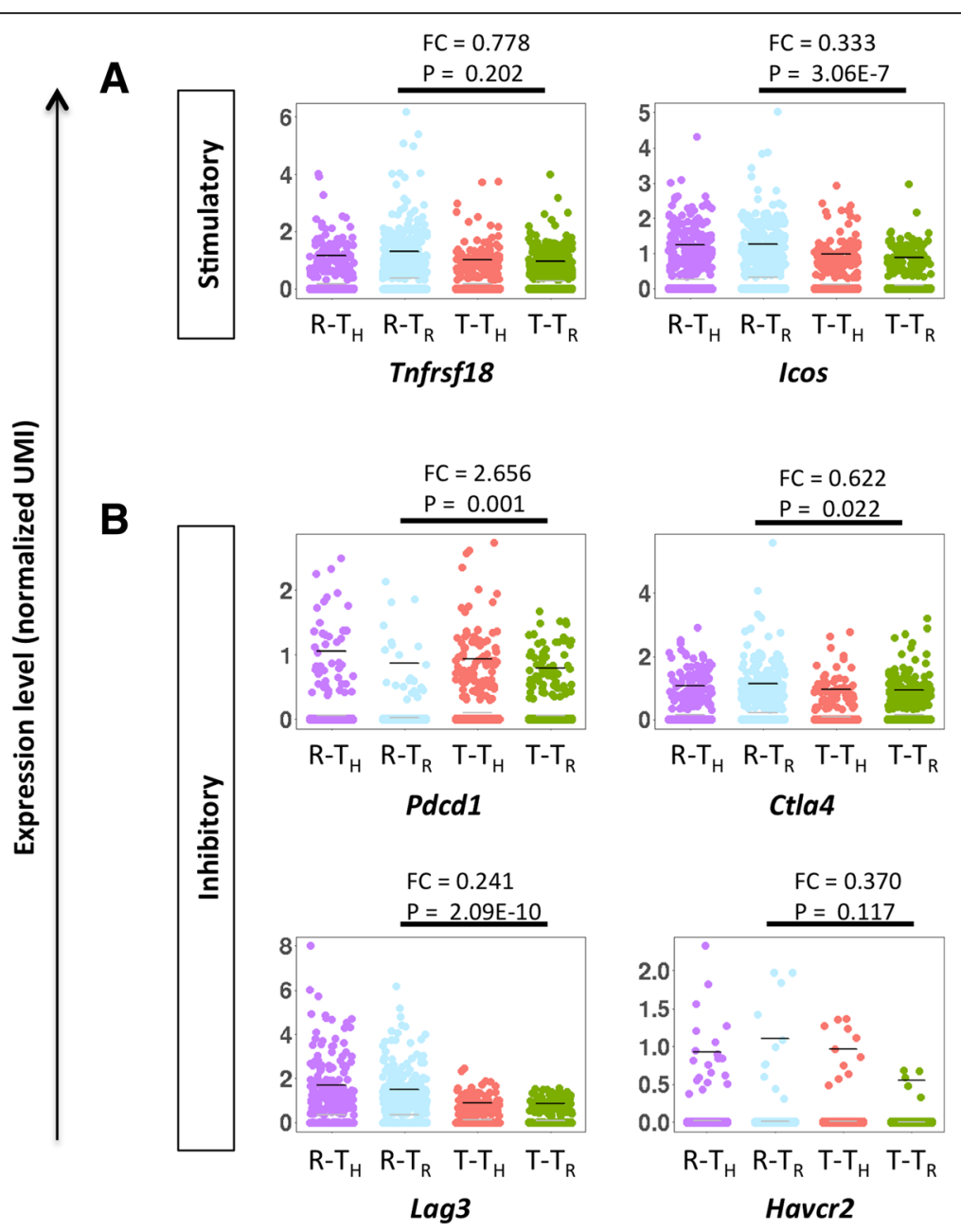

Fig. 4 Identification of immune checkpoint-specific genes expressed by $\mathrm{CD}^{+} \mathrm{T}$ cells in rejecting and tolerated grafts. Jitter plots comparing expression levels of a stimulatory and $\mathbf{b}$ inhibitory immune checkpoint-specific genes expressed by $C D 4^{+} h C D 2^{-}$Th of rejecting grafts (R- $\left.T_{H}\right)$, $C D 4^{+} h C D 2^{+}$Treg of rejecting grafts $\left(R-T_{R}\right), C D 4^{+} h C D 2^{-}$Th of tolerated grafts $\left(T_{-} T_{H}\right)$, and $C D 4^{+} h C D 2^{+}$Treg of tolerated grafts $\left(T-T_{R}\right)$. The fold change (FC) of $T-T_{R}$ over $R-T_{R}$ and the $p$ value $(P)$ by sSeq method are provided. Gray and black bars indicate the average expression level among all and expressed cells, respectively 


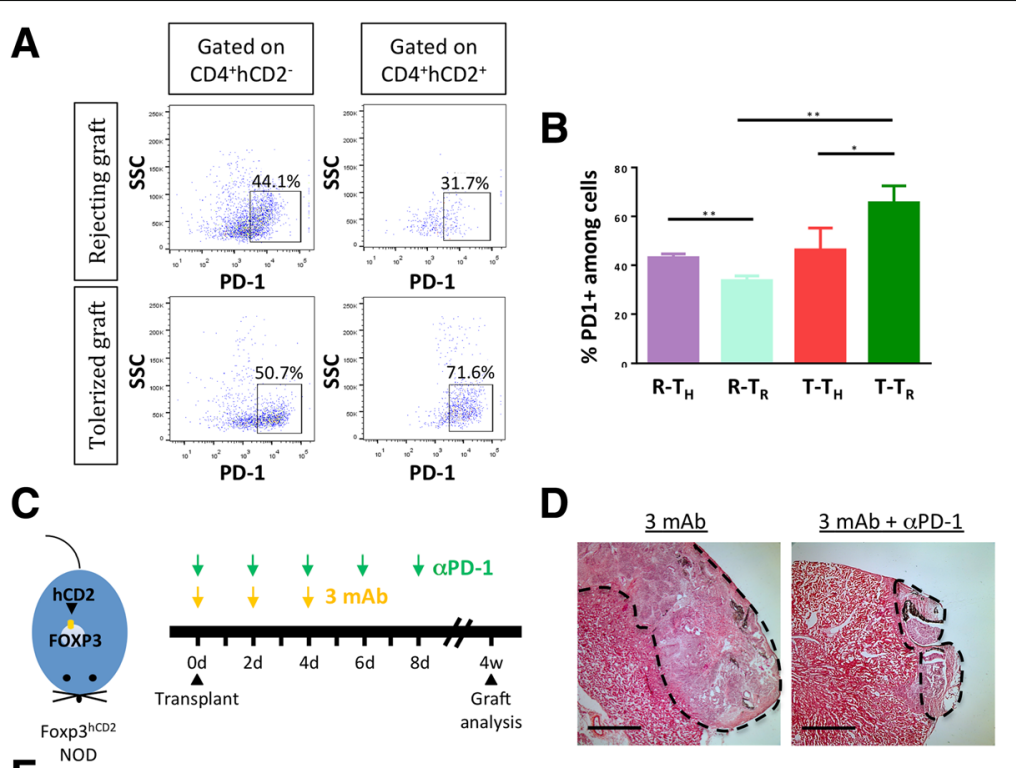

E
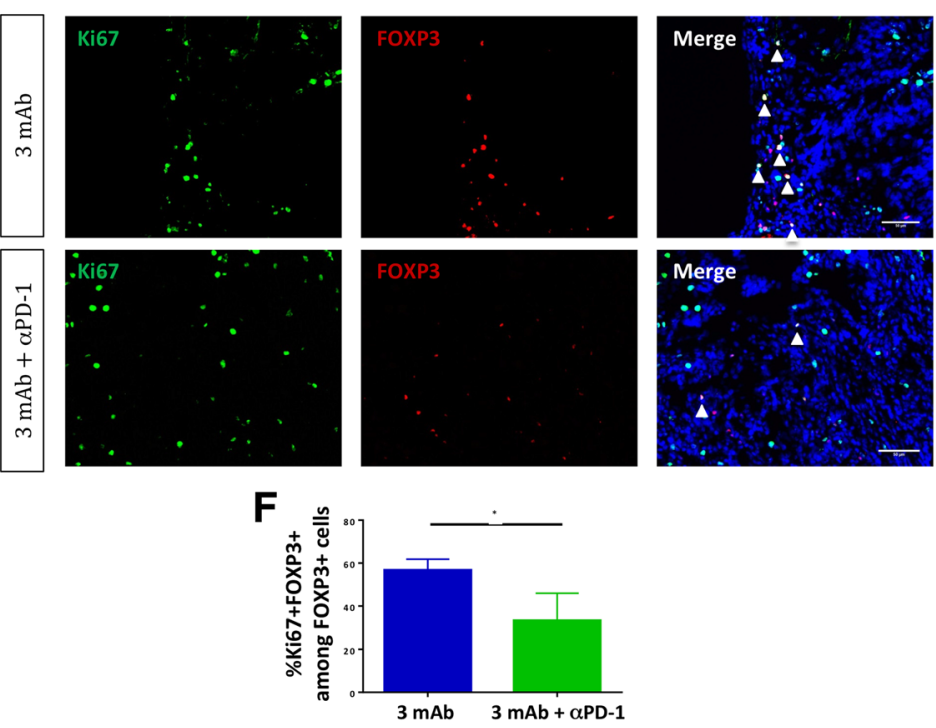

Fig. 5 Proliferation of $\mathrm{CD}^{+}$Treg in tolerated grafts requires functional PD-1 signaling. a Flow cytometric analysis and $\mathbf{b}$ quantification showing expression of PD-1 in $\mathrm{CD}^{+} h C D 2^{-}\left(T_{H}\right)$ or $\mathrm{CD}^{+} h C D 2^{+}\left(T_{R}\right)$ cells of rejecting and tolerated grafts, respectively. $\mathbf{c}$ A schematic diagram showing the protocol for antibody treatments. $\mathbf{d}$ H\&E staining showing graft rejection following treatment with aPD-1 mAb in addition to coreceptor and costimulation blockade ( $3 \mathrm{mAb}$ ). Scale bars: $1000 \mu \mathrm{m}$. e Immunostaining and $\mathbf{f}$ quantifications of Ki67 $7^{+} \mathrm{FOXP} 3^{+}$cells among total FOXP3 ${ }^{+}$cells in 3 mAb- and 3 mAb + aPD-1 mAb-treated grafts, respectively. Arrows indicate Ki67 ${ }^{+} F O X P 3^{+}$cells. Scale bars: $50 \mu m$. ${ }^{*} P<0.05$. (a-f) $n=5$ per group

significantly less $\mathrm{Ki}^{+} 7^{+} \mathrm{FOXP3}{ }^{+}$Treg were found in the 3 $\mathrm{mAb}+\alpha \mathrm{PD}-1 \mathrm{mAb}-$ than $3 \mathrm{mAb}$-treated group (Fig. 5f). Therefore, our results suggested that blocking PD-1 signaling negated the effect of coreceptor and costimulation blockade on Treg proliferation for maintaining transplant tolerance.

\section{Discussion}

Despite the large body of evidence showing that $\mathrm{CD}^{+}{ }^{+} \mathrm{FOXP} 3^{+}$Treg play an important role in maintaining transplant tolerance, clinical studies demonstrate a correlation between intragraft $\mathrm{CD}^{+}{ }^{+} \mathrm{FXX}^{+}$cells [46] or urinary FOXP3 mRNA [47] and acute renal allograft rejection. Nevertheless, whether Treg mediated transplant tolerance is a numbers game or whether they are just "failed" bystanders during transplant rejection remains unknown. Since Treg determine the outcome of both autoimmunity and transplant rejection, we transplanted surrogate tissues in NOD recipients without ongoing autoimmunity in this study. We showed that Treg were indispensable for enabling coreceptor and costimulation blockade-mediated transplant tolerance to hESC-islets in NOD.Foxp $3^{\mathrm{hCD} 2}$ recipients as their depletion with an ablative anti-hCD2 antibody led to graft rejection. We also found significantly 
more Treg resided in tolerated than rejecting grafts and showed that they were phenotypically distinct at singlecell level during transplant rejection and tolerance albeit with a common expression of the markers, CD4 and FOXP3.

Our current knowledge of Treg phenotypes is insufficient to define their cellular states correlated to transplant outcome. Recent advances in single-cell transcriptomics offer a new opportunity to discover additional subsets and cellular states of immune cells during development and disease pathogenesis at high resolution [48-50]. However, to date, there is no single-cell transcriptomic profiling data for Treg particularly in the transplantation setting. Here, we utilized the power of microfluidic scRNA-seq to establish a relatively large-scale cellular transcriptomic atlas of $\mathrm{CD}^{+} \mathrm{T}$ cells during transplantation by profiling $\sim 13,000$ cells including both conventional Th and regulator Treg from rejecting and tolerated grafts. We first analyzed data with $\sim 1000$ randomly selected cells of each group to minimize the impact of cell number biases between different groups. It is noteworthy that we also observed the same conclusion by analyzing all cells $(\sim 14,000$ cells, Additional file 1: Figure S7). Our results offered unbiased genomic classification together with phenotypic and functional validation, leading us to revise the taxonomy of these cells in determining the transplant outcome.

Transcriptomically, we did pairwise comparisons. By comparing to Th, intragraft Treg expressed less genes that activated adaptive immunity such as $\mathrm{B} / \mathrm{T}$ cell proliferation and NK cell chemotaxis during transplant tolerance. Likewise, they expressed more genes associated with negative regulation of conventional $\mathrm{T}$ cell function and less genes that activated adaptive immunity during transplant rejection. Since intragraft Treg still appeared to harbor immunomodulatory function, they were not bystanders during transplant rejection. So why might the grafts be rejected in the presence of Treg? We compared Treg derived from rejecting and tolerated grafts. Our data demonstrated cellular heterogeneity among Treg in the rejecting grafts: $48 \%$ Treg in C2 reflected a potential for chemotaxis of NK cells (Ccl3, Ccl4, Ccl5, Xcl1), monocytes (Ccl3, Ccl4, Ccl9, Ccr2, Calca, Xcl1), and neutrophils (Ccl3, Ccl4, Ccl5, Ccl9, Itga1, Pde4b, Slc37a4), and 37\% Treg in C3 reflected a potential for protein ubiquitination and responses to interferons. In fact, the chemotactic genes $\mathrm{Ccl} 5$ and Itgal were also overexpressed in splenic Treg of recipients that had rejecting grafts compared to that of the tolerated group. Furthermore, by comparing Th during rejection and tolerance, we might infer that Th negatively regulated the immune system and supported Treg function during tolerance.

Since scRNA-seq data revealed that $40 \%$ Treg of tolerated grafts were found in S-G2/M phages of the cell cycle, Treg proliferation was a possible major mechanism by which coreceptor and costimulation blockade mediated transplant tolerance. Indeed, we confirmed by immunostaining that $>80 \% \mathrm{FOXP}^{+}$cells expressed Ki67 in the tolerated grafts compared to $~ 35 \%$ in the rejecting grafts. However, the signaling pathway driving any Treg proliferation during transplant tolerance is not clear. A previous report shows that the inhibitory checkpoint molecule PD-1 is vital in maintaining peripheral tolerance as PD-1 knockout mice spontaneously develop autoimmunity with markedly augmented proliferation of conventional T cells [51]. Since PD-L1 is found upregulated in many types of tumors, and PD-1 receptor is expressed by conventional $\mathrm{T}$ cells, it was hypothesized that tumors evaded immunosurveillance through the PD-L1/PD-1 pathway. Indeed, it is well characterized that signaling through PD-1 contributes to exhaustion and dysfunction of conventional $\mathrm{T}$ cells [31, 52], and anti-PD-1 mAb-mediated immunotherapy (e.g., Nivolumab) is currently used to treat human cancers [53]. In immune regulation, PD-1 expression on Treg is found inversely correlated to their proliferation during chronic liver inflammation [54], while in another study, PD-1 signaling promotes differentiation of $\mathrm{CD}^{+}$naïve [55] or Th1 [56] cells into induced Treg (iTreg) with suppressive function. Such conversion can operate with [57] or without [55] TGF- $\beta$. Nevertheless, the direct role of PD-1 in survival and/or function of Treg is less clear.

Our scRNA-seq data with subsequent validation by flow cytometry revealed that a significantly greater percentage of Treg expressed PD-1 during transplant tolerance than rejection. We found that blocking PD-1 signaling via the neutralizing anti-PD-1 antibody abolished coreceptor and costimulation blockade-induced transplant tolerance, resulting in rejection of $\mathrm{hESC}$-derived tissues with significantly reduced proliferation of intragraft Treg. Therefore, our results suggested that PD-1 signaling could be one of the mechanisms by which antibody blockade mediated Treg proliferation. Nevertheless, it is difficult to examine the effect of PD-1 blockade on conventional T cells in the absence of Treg in the transplantation setting, as we showed that Treg were indispensable for antibody blockade-mediated immune tolerance to hESC grafts and their absence contributed to graft rejection. Given the differential expression of PD-1 on conventional T cells and Treg during transplant rejection and tolerance, there might in principle be some differential binding and therefore efficacy of anti-PD-1 antibody on conventional $\mathrm{T}$ cells and Treg during the tolerance induction process. Our results suggest a therapeutic potential of PD-1 agonists in promoting transplant tolerance to $\mathrm{hESC}$-derived tissues given their effect in facilitating self-renewal of Treg. Indeed, a previous report demonstrated that overexpression of PD-L1 prevents transplant rejection of mouse islets [58]. 
Whether the same regime could prevent rejection of human islets awaits further investigations. Although the role of therapeutic anti-PD-1 antibody on Treg has yet to be studied in cancer patients [59], our results also give new insights into the unwanted side effect of PD-1 blockade that may limit self-renewal of Treg during cancer treatment. Since Treg suppress autoreactive T cells, PD-1 blockade may cause autoimmune attack as seen in cancer patients who received anti-PD-1 antibodies and developed T1D and other autoimmune diseases [30].

\section{Conclusions}

Taken together, we have demonstrated that coreceptor and costimulation blockade induced transplant tolerance to hESC-derived pancreatic islets in NOD mouse recipients by promoting Treg proliferation via the PD-1 signaling pathway. These findings pave the way for clinical development of hESC-derived pancreatic tissues, combined with immunotherapies that expand intragraft Treg, as a potential treatment for alleviating autoimmunity in T1D. Our revised taxonomy of Treg during transplant rejection and tolerance might also enable more accurate monitoring of the outcome of solid organ transplantation.

\section{Additional file}

Additional file 1: Single-cell transcriptomics reveal that PD-1 mediates immune tolerance by regulating proliferation of regulatory $T$ cells, Supplementary Figures S1-7 and Tables S1-6. (DOCX 13159 kb)

\section{Acknowledgements}

We thank Dr. Joaquim S.L. Vong, Dr. Ji Lu, and Jiatao Li (CUHK) for their technical help throughout the study. We also thank Prof. Stephen Tsui (CUHK) for his machinery support.

\section{Funding}

This work was supported by the Research Grants Council of Hong Kong (04110515, 14111916, C4024-16W, C4026-17WF); Health and Medical Research Fund (03140346, 04152566); Croucher Foundation (Innovation Award and Start-up Allowance); Direct Grant, Faculty Innovation Award, Seed Fund from Lui Chi Woo Institute of Innovative Medicine, postdoctoral fellowship (K.Y.Y.); and postgraduate studentships (C.S.L. and X.L.) from CUHK.

\section{Availability of data and materials}

scRNAseq data are deposited under NCBI BioProject (ID: PRJNA489319).

\section{Authors' contributions}

CSL, XL, WWC, and MK performed the experiments. KYY performed bioinformatics analysis. $C S L, X L$, and $K O L$ analyzed the experimental data. HW and SH provided the reagents. JCHT and YMDL provided support for scRNAseq platform. KOL designed the research and wrote the manuscript. All authors read and approved the final manuscript.

\section{Ethics approval}

All animal procedures were approved by the CUHK Animal Experimentation Ethics Committee and performed in compliance with the Guide for the Care and Use of Laboratory Animals (NIH publication, eighth edition, updated 2011). The use of hESC lines does not require additional ethical approval by our institute.

\section{Consent for publication}

N/A

\section{Competing interests}

The authors declare that they have no competing interests.

\section{Publisher's Note}

Springer Nature remains neutral with regard to jurisdictional claims in published maps and institutional affiliations.

\section{Author details}

1Department of Chemical Pathology, Prince of Wales Hospital, The Chinese University of Hong Kong, Hong Kong, China. ${ }^{2}$ Department of Paediatrics and Adolescent Medicine, Division of Paediatric Hematology and Oncology, Faculty of Medicine, Medical Center, University of Freiburg, Freiburg im Breisgau, Germany. ${ }^{3}$ Sir William Dunn School of Pathology, University of Oxford, Oxford, UK. ${ }^{4}$ Laboratory of Immunology and Microbiology, Graduate School of Pharmaceutical Sciences, The University of Tokyo, Tokyo, Japan. ${ }^{5} \mathrm{Li}$ Ka Shing Institute of Health Sciences, Prince of Wales Hospital, The Chinese University of Hong Kong, Hong Kong, China.

Received: 15 January 2018 Accepted: 7 September 2018

Published online: 20 September 2018

\section{References}

1. Sharir R, Semo J, Shaish A, Landa-Rouben N, Entin-Meer M, Keren G, et al. Regulatory $T$ cells influence blood flow recovery in experimental hindlimb ischaemia in an IL-10-dependent manner. Cardiovasc Res. 2014;103(4):585-96.

2. Gamble JM, Simpson SH, Eurich DT, Majumdar SR, Johnson JA. Insulin use and increased risk of mortality in type 2 diabetes: a cohort study. Diabetes Obes Metab. 2010;12(1):47-53.

3. Shapiro AM, Ricordi C, Hering BJ, Auchincloss H, Lindblad R, Robertson RP, et al. International trial of the Edmonton protocol for islet transplantation. N Engl J Med. 2006;355(13):1318-30.

4. Bellin MD, Barton FB, Heitman A, Harmon JV, Kandaswamy R, Balamurugan AN, et al. Potent induction immunotherapy promotes long-term insulin independence after islet transplantation in type 1 diabetes. Am J Transplant Off J Am Soc Transplant Am Soc Transplant Surg. 2012;12(6):1576-83.

5. Monti P, Scirpoli M, Maffi P, Ghidoli N, De Taddeo F, Bertuzzi F, et al. Islet transplantation in patients with autoimmune diabetes induces homeostatic cytokines that expand autoreactive memory T cells. J Clin Invest. 2008; 118(5):1806-14.

6. Pagliuca FW, Millman JR, Gurtler M, Segel M, Van Dervort A, Ryu JH, et al. Generation of functional human pancreatic beta cells in vitro. Cell. 2014; 159(2):428-39.

7. Rezania A, Bruin JE, Arora P, Rubin A, Batushansky I, Asadi A, et al. Reversal of diabetes with insulin-producing cells derived in vitro from human pluripotent stem cells. Nat Biotechnol. 2014;32(11):1121-33.

8. Szot GL, Yadav M, Lang J, Kroon E, Kerr J, Kadoya K, et al. Tolerance induction and reversal of diabetes in mice transplanted with human embryonic stem cell-derived pancreatic endoderm. Cell Stem Cell. 2015; 16(2):148-57.

9. Pearl Jl, Lee AS, Leveson-Gower DB, Sun N, Ghosh Z, Lan F, et al. Short-term immunosuppression promotes engraftment of embryonic and induced pluripotent stem cells. Cell Stem Cell. 2011;8(3):309-17.

10. Schwartz SD, Regillo CD, Lam BL, Eliott D, Rosenfeld PJ, Gregori NZ, et al. Human embryonic stem cell-derived retinal pigment epithelium in patients with age-related macular degeneration and Stargardt's macular dystrophy: follow-up of two open-label phase 1/2 studies. Lancet. 2015; 385(9967):509-16.

11. Schwartz SD, Hubschman JP, Heilwell G, Franco-Cardenas V, Pan CK, Ostrick $\mathrm{RM}$, et al. Embryonic stem cell trials for macular degeneration: a preliminary report. Lancet. 2012;379(9817):713-20

12. Rong Z, Wang M, Hu Z, Stradner M, Zhu S, Kong H, et al. An effective approach to prevent immune rejection of human ESC-derived allografts. Cell Stem Cell. 2014;14(1):121-30.

13. Lui KO, Howie D, Ng SW, Liu S, Chien KR, Waldmann H. Tolerance induction to human stem cell transplants with extension to their differentiated progeny. Nat Commun. 2014:5:5629.

14. Vegas AJ, Veiseh O, Gurtler M, Millman JR, Pagliuca FW, Bader AR, et al. Long-term glycemic control using polymer-encapsulated human stem cellderived beta cells in immune-competent mice. Nat Med. 2016;22(3):306-11. 
15. Lui KO, Bu L, Li RA, Chan CW. Pluripotent stem cell-based heart regeneration: from the developmental and immunological perspectives. Birth Defects Res C Embryo Today. 2012;96(1):98-108.

16. Lui KO, Waldmann H, Fairchild PJ. Embryonic stem cells: overcoming the immunological barriers to cell replacement therapy. Curr Stem Cell Res Ther. 2009:4(1):70-80.

17. Lui KO, Fairchild PJ, Waldmann H. Prospects for ensuring acceptance of ES cell-derived tissues. Cambridge (MA): StemBook; 2008.

18. Lui KO, Boyd AS, Cobbold SP, Waldmann H, Fairchild PJ. A role for regulatory T cells in acceptance of ESC-derived tissues transplanted across an major histocompatibility complex barrier. Stem Cells. 2010;28(10):1905-14.

19. Schulz TC. Concise review: manufacturing of pancreatic endoderm cells for clinical trials in type 1 diabetes. Stem Cells Transl Med. 2015;4(8):927-31.

20. Agulnick AD, Ambruzs DM, Moorman MA, Bhoumik A, Cesario RM, Payne JK, et al. Insulin-producing endocrine cells differentiated in vitro from human embryonic stem cells function in macroencapsulation devices in vivo. Stem Cells Transl Med. 2015:4(10):1214-22.

21. Basta G, Montanucci P, Luca G, Boselli C, Noya G, Barbaro B, et al. Long-term metabolic and immunological follow-up of nonimmunosuppressed patients with type 1 diabetes treated with microencapsulated islet allografts: four cases. Diabetes Care. 2011;34(11):2406-9.

22. Calafiore R, Basta G, Luca G, Lemmi A, Montanucci MP, Calabrese G, et al. Microencapsulated pancreatic islet allografts into nonimmunosuppressed patients with type 1 diabetes: first two cases. Diabetes Care. 2006;29(1):137-8.

23. Tuch BE, Keogh GW, Williams LJ, Wu W, Foster JL, Vaithilingam V, et al. Safety and viability of microencapsulated human islets transplanted into diabetic humans. Diabetes Care. 2009;32(10):1887-9.

24. de Groot M, Schuurs TA, van Schilfgaarde R. Causes of limited survival of microencapsulated pancreatic islet grafts. J Surg Res. 2004;121(1):141-50

25. Brunkow ME, Jeffery EW, Hjerrild KA, Paeper B, Clark LB, Yasayko SA, et al. Disruption of a new forkhead/winged-helix protein, scurfin, results in the fatal lymphoproliferative disorder of the scurfy mouse. Nat Genet. 2001;27(1):68-73.

26. Di lanni M, Falzetti F, Carotti A, Terenzi A, Castellino F, Bonifacio E, et al. Tregs prevent GVHD and promote immune reconstitution in HLAhaploidentical transplantation. Blood. 2011;117(14):3921-3928. https://www. ncbi.nlm.nih.gov/pubmed/21292771.

27. Kendal AR, Chen Y, Regateiro FS, Ma J, Adams E, Cobbold SP, et al. Sustained suppression by Foxp3+ regulatory T cells is vital for infectious transplantation tolerance. J Exp Med. 2011;208(10):2043-53.

28. Qin S, Cobbold SP, Pope H, Elliott J, Kioussis D, Davies J, et al. "Infectious" transplantation tolerance. Science. 1993;259(5097):974-7.

29. Davies JD, Leong LY, Mellor A, Cobbold SP, Waldmann H. T cell suppression in transplantation tolerance through linked recognition. J Immunol. 1996; 156(10):3602-7.

30. Couzin-Frankel J. Autoimmune diseases surface after cancer treatment. Science. 2017;358(6365):852.

31. Tumeh PC, Harview CL, Yearley JH, Shintaku IP, Taylor EJ, Robert L, et al. PD1 blockade induces responses by inhibiting adaptive immune resistance. Nature. 2014;515(7528):568-71

32. Miyao T, Floess $\mathrm{S}$, Setoguchi R, Luche $\mathrm{H}$, Fehling HJ, Waldmann $\mathrm{H}$, et al. Plasticity of Foxp3(+) T cells reflects promiscuous Foxp3 expression in conventional T cells but not reprogramming of regulatory T cells. Immunity. 2012;36(2):262-75.

33. Baas M, Besancon A, Goncalves T, Valette F, Yagita H, Sawitzki B, et al. TGFbeta-dependent expression of PD-1 and PD-L1 controls CD8(+) T cell anergy in transplant tolerance. elife. 2016;5:e08133.

34. Leung OM, Li J, Li X, Chan WW, Yang KY, Ku M, et al. Regulatory T cells promote apelin-mediated sprouting angiogenesis in type 2 diabetes. Cell Rep. 2018;24(6):1610-26.

35. Dobin A, Davis CA, Schlesinger F, Drenkow J, Zaleski C, Jha S, et al. STAR: ultrafast universal RNA-seq aligner. Bioinformatics. 2013;29(1):15-21.

36. Heinz S, Benner C, Spann N, Bertolino E, Lin YC, Laslo P, et al. Simple combinations of lineage-determining transcription factors prime cisregulatory elements required for macrophage and B cell identities. Mol Cell. 2010;38(4):576-89.

37. Huang da W, Sherman BT, Lempicki RA. Bioinformatics enrichment tools: paths toward the comprehensive functional analysis of large gene lists. Nucleic Acids Res. 2009;37(1):1-13.
38. Zheng GX, Terry JM, Belgrader P, Ryvkin P, Bent ZW, Wilson R, et al. Massively parallel digital transcriptional profiling of single cells. Nat Commun. 2017:8:14049.

39. Yu D, Huber W, Vitek O. Shrinkage estimation of dispersion in Negative Binomial models for RNA-seq experiments with small sample size. Bioinformatics. 2013;29(10):1275-82.

40. Lun AT, McCarthy DJ, Marioni JC. A step-by-step workflow for low-level analysis of single-cell RNA-seq data with Bioconductor. F1000Res. 2016;5:2122.

41. Yi Z, Diz R, Martin AJ, Morillon YM, Kline DE, Li L, et al. Long-term remission of diabetes in NOD mice is induced by nondepleting anti-CD4 and antiCD8 antibodies. Diabetes. 2012;61(11):2871-80.

42. Graca L, Cobbold SP, Waldmann $\mathrm{H}$. Identification of regulatory T cells in tolerated allografts. J Exp Med. 2002;195(12):1641-6.

43. Tsang JCH, Vong JSL, Ji L, Poon LCY, Jiang P, Lui KO, et al. Integrative singlecell and cell-free plasma RNA transcriptomics elucidates placental cellular dynamics. In: Proceedings of the National Academy of Sciences of the United States of America; 2017.

44. Vences-Catalan F, Rajapaksa R, Srivastava MK, Marabelle A, Kuo CC, Levy R, et al. Tetraspanin CD81 promotes tumor growth and metastasis by modulating the functions of T regulatory and myeloid-derived suppressor cells. Cancer Res. 2015;75(21):4517-26.

45. Schneider MA, Meingassner JG, Lipp M, Moore HD, Rot A. CCR7 is required for the in vivo function of $\mathrm{CD} 4+\mathrm{CD} 25+$ regulatory $\mathrm{T}$ cells. J Exp Med. 2007:204(4):735-45.

46. Veronese F, Rotman S, Smith RN, Pelle TD, Farrell ML, Kawai T, et al. Pathological and clinical correlates of FOXP3+ cells in renal allografts during acute rejection. Am J Transplant Off J Am Soc Transplant Am Soc Transplant Surg. 2007;7(4):914-22.

47. Muthukumar T, Dadhania D, Ding R, Snopkowski C, Naqvi R, Lee JB, et al. Messenger RNA for FOXP3 in the urine of renal-allograft recipients. N Engl J Med. 2005;353(22):2342-51.

48. Lavin Y, Kobayashi S, Leader A, Amir ED, Elefant N, Bigenwald C, et al. Innate immune landscape in early lung adenocarcinoma by paired single-cell analyses. Cell. 2017;169(4):750-65 e17.

49. Proserpio V, Piccolo A, Haim-Vilmovsky L, Kar G, Lonnberg T, Svensson $V$, et al. Single-cell analysis of CD4+ T-cell differentiation reveals three major cell states and progressive acceleration of proliferation. Genome Biol. 2016;17:103.

50. Villani AC, Satija R, Reynolds G, Sarkizova S, Shekhar K, Fletcher J, et al. Single-cell RNA-seq reveals new types of human blood dendritic cells, monocytes, and progenitors. Science. 2017;356(6335). https://doi.org/10. 1126/science.aah4573.

51. Nishimura H, Nose M, Hiai H, Minato N, Honjo T. Development of lupus-like autoimmune diseases by disruption of the PD-1 gene encoding an ITIM motif-carrying immunoreceptor. Immunity. 1999;11(2):141-51.

52. Wei F, Zhong S, Ma Z, Kong H, Medvec A, Ahmed R, et al. Strength of PD-1 signaling differentially affects T-cell effector functions. Proc Natl Acad Sci U S A. 2013;110(27):E2480-9.

53. Chen L, Han X. Anti-PD-1/PD-L1 therapy of human cancer: past, present, and future. J Clin Invest. 2015;125(9):3384-91.

54. Franceschini D, Paroli M, Francavilla V, Videtta M, Morrone S, Labbadia G, et al. PD-L1 negatively regulates CD4+CD25+Foxp3+ Tregs by limiting STAT-5 phosphorylation in patients chronically infected with HCV. J Clin Investig. 2009;119(3):551-64.

55. Francisco LM, Salinas VH, Brown KE, Vanguri VK, Freeman GJ, Kuchroo VK, et al. PD-L1 regulates the development, maintenance, and function of induced regulatory T cells. J Exp Med. 2009;206(13):3015-29.

56. Amarnath S, Mangus CW, Wang JC, Wei F, He A, Kapoor V, et al. The PDL1PD1 axis converts human TH1 cells into regulatory T cells. Sci Transl Med. 2011;3(111):111ra20.

57. Wang L, Pino-Lagos K, de Vries VC, Guleria I, Sayegh MH, Noelle RJ. Programmed death 1 ligand signaling regulates the generation of adaptive Foxp3+CD4+ regulatory T cells. Proc Natl Acad Sci U S A. 2008;105(27):9331-6.

58. Li T, Ma R, Zhu JY, Wang FS, Huang L, Leng XS. PD-1/PD-L1 costimulatory pathway-induced mouse islet transplantation immune tolerance. Transplant Proc. 2015:47(1):165-70.

59. Tanaka A, Sakaguchi S. Regulatory T cells in cancer immunotherapy. Cell Res. 2017;27(1):109-18. 